\title{
ПРОДВИЖЕНИЕ ШКОЛЫ ВОКАЛА С ПОМОЩЬЮ СОЦИАЛЬНОЙ СЕТИ INSTAGRАМ
}

\author{
Щетинина Нина Николаевна \\ кандидат политологических наук \\ РОСИИЙСКИЙ ГОСУДАРСТВЕННЫЙ СОЦИАЛЬНЫЙ УНИВЕРСИТЕТ \\ $(Р Г C У)$ \\ Россия, г. Москва \\ Павлова Анастасия Алексеевна \\ Студентка 4 курса \\ РОСИИЙСКИЙ ГОСУДАРСТВЕННЫЙ СОЦИАЛЬНЫЙ УНИВЕРСИТЕТ \\ $(Р Г C У)$ \\ Россия, г. Москва
}

\begin{abstract}
Аннотация. В данной статье рассматриваются актуальность и эффективность использования социальной сети Instagram в бизнесе, а также способы продвижения организации дополнительного музыкального образования, а именно школы вокала. Услуги подобных организаций пользуются немалым спросом, целевая аудитория это не только дети школьного возраста, желающие подготовиться к поступлению в высшее учебное заведение. Эта школа вокала помогает развить музыкальные способности, будь это новичок или профессионал.

Новизна проведенного исследования состоит в использовании социальной сети Instagram в качестве инструмента маркетинга. Кроме развлекательных функций рассматриваемой социальной сети, стоит принять во внимание ее перспективное свойство продвижения и закрепления собственного бизнеса. Мир социальных сетей давно шагнул в сторону развития в рекламе, пиаре и журналистике. Пользователи Instagram могут не только, якобы, тратить время в пустую, за просмотром пестрящих, фильтрованных картинок, но и извлечь пользу для себя и других.

Abstract. This article discusses the relevance and effectiveness of using the social network Instagram in business, as well as ways to promote the organization of additional music education, namely the vocal school. The services of such organizations are in considerable demand, the target audience is not only school-age children who want to prepare for admission to a higher educational institution. This vocal school helps to develop musical abilities, whether it is a novice or a professional. The novelty of the study is the use of the social network Instagram as a marketing tool. In addition to the entertainment functions of the social network in question, it is worth taking into account its promising property of promoting and consolidating its own business. The world of social networks has long stepped towards development in advertising, PR and journalism. Instagram users can not only allegedly spend time empty, watching motley, filtered pictures, but also benefit themselves and others.
\end{abstract}

Ключевые слова: социальные сети, Instagram, продвижение, бизнес, контент, образование

Key words: social networks, Instagram, promotion, business, content, education

Instagram - на данный момент, это одна из самых популярных площадок для продвижения самого себя, своего бизнеса или же всего вместе. Социальная сеть за годы существования Instagram в России, а это уже с 2010 года, прошла огромное количество изменений. Помимо смены значка приложения, его внешнего вида в целом, то есть оформления страницы, добавили множество приятных, а главное удобных функций. Это возможность загружать более длительные сторис, и видеоролики на страницу до 10 минут, а прямые эфиры аж до 60 минут.

Не отставая от знаменитого TikTok, в Instagram также появилась возможность создавать небольшие видеоролики, идущие сплошным потоком в ленте Reels, куда абсолютно любой пользователь сможет посмотреть, либо же создать свой собственный Reels видеоролик, останется только подобрать аудиодорожку, либо оставить оригинальный звук, подобрать фильтр, или же не использовать его вообще - все в руках пользователей, во всех смыслах.

Помимо личного использования в качестве развлекательного инструмента, Instagram широко используется как полноценная платформа для рекламы, для организаций, желающих набрать аудиторию и продать свой товар именно в Instagram, так как он вмещает в себя самую разную целевую аудиторию, начиная от 13 лет (судя по правилам регистрации в Instagram) и до бесконечности.

\section{Начало формирования бизнес-аккаунта}

Соответственно, качественный бизнес-аккаунт в Instagram мы готовы создать, если:

- будем готовы тратить время на этот аккаунт

- правильно определим ЦА

- поймем, с какой целью создается этот аккаунт

- определим, что будет включено контент

- определим форматы подачи информации 
- определим инструменты для дополнительного распространения контента (использование других социальный сетей никто не запрещал)

- определим способы доступной нам рекламы аккаунта

Конкретные цели дают конкретные результаты, но не стоит после публикации первого же поста ждать и надеяться изо всех сил, что сейчас он сразу соберет много лайков, просмотров, комментариев. Кто-то годами набирает аудиторию, не стоит ждать чуда, но и бросать сразу после «незалайконного» поста не стоит. Помимо этого не стоит пренебрегать благоразумием ведения Instagram-аккаунта. Что это значит?

Есть перечень вещей, которые элементарно запрещено публиковать в Instagram, да и в социальных сетях в целом:

- навязчивый спам

- рассылки

- включение рандомных пользователей в беседы и сообщества без их согласия

- плагиат

- использование логотипа Instagram в неуместных целях

- публикация контента насильственного, эротического характера

- пропаганда

и так далее.

Если не хочется потерять свой аккаунт, дав возможность модераторам, неудачным постом или фотографией отправить ваш аккаунт в «бан», как во временный, так и без возможности его восстановления, лучше не рисковать, а сразу и изучить все тонкости и правила его ведения.

Особенности продвижения Instagram - аккаунта школы вокала

После анализа страниц конкурентов, были определены дальнейшие шаги для развития Instagram - aккаунта и в исправлении ошибок текущего ведения страницы:

1. Создать собственный логотип организации, олицетворяющий название и деятельность организации в целом; также логотип сможем послужить как водяной знак для всех публикаций.

2. Сменить фото профиля, либо сделать свою, в духе оформления страницы, либо поставить логотип организации.

3. Изменить шапку профиля, исправить ссылку на доступ к «записи на бесплатное занятие»; распределить основные тезисы и отметить их смайлами, возможно, сделать записи индивидуальным шрифтом.

4. Для «Акутального», под шапкой профиля, сделать одинаковые иконки, чтобы все было в едином стиле.

5. Завести собственный хештег организации, добавить его под каждой публикацией.

6. Отмечать клиентов школы вокала под публикациями, на которых они отображены, отзывы клиентов также публиковать на странице, с визуальным упоминанием аккаунта человека, который написал отзыв; можно добавить отдельный хештег для отзывов об организации, сделать индивидуальное оформление для отзывов, если клиент написал отзыв в «сообщениях» (просто скриншот отзыва из WhatsApp или Direct Instagram не подойдет.

\section{Идеи контента для профиля школы вокала}

Проанализировав существующие профили вокальных школ, была разработана концепция ведения страницы в Instagram, со следующими видами контента:

1. Продающий

- отдельно сформированные посты с реальными отзывами клиентов;

- $\quad$ репосты отзывов клиентов с их страниц;

- информация о сертификатах и скидках на занятия;

- посты об открытии новый вокальных групп (семейный вокал, групповые занятия, вокал для детей);

- анонсы мероприятий, концертов.

2. Информационный

- полезные советы, лайфхаки, касательно вокала, они могут быть

- оформлены как инфографика, либо сняты в видео-формате (какая должна быть осанка при пении, что нельзя есть перед уроком пения, почему нельзя петь на морозе и так далее);

- $\quad$ разъяснения эффективных методик преподавания вокала от преподавателей школы (наглядные примеры с учениками в видео-формате);

- материалы о том, как проходят занятия в разных группах с разными методиками;

- истории и цитаты знаменитых людей, которые когда-то учились петь;

- «вопрос-ответ» с преподавателями и учениками школы на тему процесса обучения вокалу, почему человек решил начал учиться петь, пел ли он с детства и так далее;

- знакомство с преподавателями школы (мини-интервью, фотосессии с цитатами, советами, мыслями);

3. Развлекательный 
- видео-ролики о возможных сменах интерьера в школе;

- выпуск развлекательных мемов на тему вокала;

- $\quad$ настроение и атмосфера занятий в школе, или как проходят походы в караоке

- $\quad$ снятие видео-роликов в формате Reels с использованием известных популярных аудиодорожек (следование определенным трендам, но не всем подряд, а касательно пения);

- публикация в формате «правда-ложь»;

- публикация «блиц-опросов», для подогревания интереса у аудитории (подготовка к публикации полноценных интервью);

- игра с подписчиками «Продолжите фразу»;

- публикация «ляпов» со съемок интервью и других видео-роликов;

- публикации-напоминания об интересных праздниках (в «день объятий» выходит видео-ролик с объятиями)

\section{Вывод}

Исходя из всего вышеизложенного, можно сделать вывод о том, что Instagram сможет полноценно послужить хорошим инструментом для продвижения школы вокала. Так как подобные организации пользуются спросом, a Instagram, как мы помним, одна из самых популярных и удобных социальных сетей. При грамотной проработке плана действий по развитию и продвижению страницы в Instagram, можно набрать широкую, заинтересованную в товаре аудиторию.

\section{Список литературы}

1. Дмитрий Анатольевич Шевченко // Цифровой маркетинг - микс. Учебник: http://www.litres.ru/pages/biblio_book/?art=66486848 ISBN 9785005539595 - [Электронный ресурс] 472 c.

2. Алексунин, В. А. Маркетинг : учебник / В. А. Алексунин. - 6-е изд., стер. - Москва : Дашков и К, 2019. - 200 с. : ил. - Режим доступа: по подписке. - URL: https://biblioclub.ru/index.php?page=book\&id=573217 Библиогр. в кн. - ISBN 978-5-394-03163-2. - [Электронный ресурс]

3. Ограбление Instagram PRO. Как создать и быстро вывести на прибыль бизнес-аккаунт / А. Соколовский — «Эксмо», 2021 - (Бизнес. Как это работает в России) 310 с. - [Электронный ресурс]

4. Поп-арт маркетинг: Insta-грамотность и контент-стратегия / Л. Нилова — «АСТ», 2017 - (Звезда Рунета. Бизнес) 140 с. - [Электронный ресурс]

5. Инстаграм: хочу likes и followers / И. Гогохия — «АСТ», 2018, 120 с. - [Электронный ресурс] 